\title{
A inércia estrutural da base produtiva brasileira: $o$ IDE e a transferência internacional de tecnologia
}

\author{
The structural inertia in the national productive base: \\ the FDI and the international transference of technology
}

TULIO CHIARINI*

\begin{abstract}
RESUMO: O que pode explicar o fato de ter havido uma entrada maciça de IDE no Brasil e ter-se mantido uma inercial estrutural na base produtiva nacional? Existe uma série de fatos macroeconômicos que podem ajudar a explicar essa inércia, como a baixa taxa de investimento e a falta de ordenação dos preços-chave da economia (como taxas de juros e taxa de câmbio), mas a proposição aqui feita é que existe um problema microeconômico estrutural relevante: falta de aptidão tecnológica das empresas industriais brasileiras. Para analisar tal proposição parte-se da separação entre os tipos de IDE (greenfield, fusão e aquisição e 'em carteira') e os tipos de canais de transferência de tecnologia (horizontal e vertical). A partir de elementos empíricos e históricos constrói-se o argumento de que a falta de aptidão tecnológica é elemento-chave no entendimento da perda de dinamismo da indústria nacional.
\end{abstract}

PALAVRAS-CHAVE: transferência de tecnologia; aptidão tecnológica; investimento direto externo.

ABSTRACT: What can explain the fact that there was a massive entry of FDI in Brazil and it remains with a structural inertia in the national productive base? There is a series of macroeconomic facts that can help explain this inertia, such as low investment rate and the mismatching of key prices in the economy (such as interest rates and exchange rates), but the proposal made here is that there is a relevant microeconomic structural problem: lack of technological capability of Brazilian industrial firms. To analyze this proposition we separate the types of FDI (greenfield, merger and acquisition and portfolio) and the types of technology transfer channels (horizontal and vertical). From empirical and historical elements we build up the argument that the lack of technological capability is a key element in understanding the dynamism loss of the domestic industry.

KEYWORDS: technology transfer; technological capability; foreign direct investment.

JEL Classification: O10; O30; O33.

\footnotetext{
"Instituto Nacional de Tecnologia - INT, Ministério da Ciência, Tecnologia e Inovação - MCTI, e-mail: tulio.chiarini@int.gov.br. Submetido: 8/Dezembro/2014; Aprovado: 7/julho/2015.

Os pensamentos e ideias expressos neste trabalho não refletem necessariamente aqueles do INT/MCTI. O autor gostaria de agradecer os pareceristas anônimos da REP pelas contribuições. Os eventuais erros são de inteira responsabilidade do autor. Esse artigo é baseado em ideias e pensamentos apresentados na Tese de Doutoramento do mesmo autor, intitulada "Transferência internacional da tecnologia: interpretações e reflexões. O caso brasileiro no Paradigma das TICs na última década do século XX e no alvorecer do século XXI", defendida no Instituto de Economia da Universidade Estadual de Campinas.
} 


\section{INTRODUÇÃO}

O IDE é um 'pacote' que envolve as finanças, mas também inclui tecnologia, organização, marketing etc. É um fluxo de capital que possui relativamente menor liquidez pelo fato de estar vinculado a ativos instrumentais (Carneiro, 2002) e por estar vinculado a tais ativos está também ligado à transferência de tecnologia. No que se refere à transferência de tecnologia, ela pode ocorrer de forma vertical ou horizontal. A primeira refere-se às transferências entre as matrizes estrangeiras e suas filiais/subsidiárias, enquanto a última, das matrizes (e/ou filiais/subsidiárias) com outras empresas locais (fornecedoras, por exemplo).

O principal meio de inserção do IDE no país receptor ocorre na forma de investimento tipo greenfield (construção de novos ativos), na forma de fusões e aquisições (F\&A) de ativos públicos e privados (já constituídos) e na forma de investimentos 'em carteira' (aportes de capital não destinado ao controle operacional da empresa, mas às transações financeiras especulativas em mercados bursáteis).

Essas classificações para fins analíticos (transferência vertical e horizontal de tecnologia e IDE do tipo greenfield, F\&A e 'em carteira') ajudam a caracterizar o fluxo internacional de tecnologia via IDE. Por exemplo, o IDE pode não estar ligado a investimentos na construção de novos ativos (greenfield), mas na forma de investimentos 'em carteira' para fins especulativos, portanto, sua efetividade em transferir tecnologia é um tanto quanto reduzida (ou nula). Além disso, supondo que haja IDE do tipo greenfield, pode haver apenas transferência de tecnologia estritamente vertical, sem gerar transferência horizontal.

A proposição aqui feita é a seguinte: embora haja um volume crescente de entrada de IDE para o Brasil (conforme será corroborado no decorrer deste artigo), parte substancial não é para construção de novos ativos e grande parte da tecnologia transferida (via IDE) ocorre verticalmente. Um problema relevante que deve estar no centro das discussões é a baixa aptidão tecnológica causadora da inércia estrutural da base produtiva nacional.

Obviamente existe uma série de fatos conjunturais macroeconômicos que podem explicar a inercial estrutural da base produtiva nacional, no entanto, a proposição aqui feita é que existe um problema microeconômico não negligenciável no Brasil: falta de aptidão tecnológica das empresas industriais nacionais. Para analisar essa proposição parte-se da apresentação de alguns conceitos relevantes para a discussão: o que é tecnologia e o que é sua transferência. Essa discussão é feita logo a seguir. Posteriormente, apresenta-se o IDE no caso brasileiro, buscando elementos empíricos que comprovem seu crescente influxo no país. Finalmente, busca-se encontrar elementos históricos que demonstram a falta de (ou pouca) aptidão tecnológica das empresas industriais nacionais, além de apresentar elementos empíricos que corroborem essa afirmação. O objetivo do trabalho não é fazer uma análise da entrada de IDE propriamente dito, mas apontar os limites do fluxo de IDE para a transferência de tecnologia no caso brasileiro. Conclui-se este trabalho com algumas considerações finais. 


\section{ALGUNS CONCEITOS}

\section{A tecnologia}

A tecnologia pode ser entendida como um conjunto sistêmico e ordenado de informações (ou seja, conhecimentos codificados e/ou tácitos) para a manufatura de produtos, aplicação de um processo e realização de serviços (sendo esses os propósitos). Esse conjunto sistêmico de informações abrange o conhecimento técnico-científico - no qual o produto final é baseado -, a capacidade organizacional para converter os insumos produtivos relevantes em itens ou serviços acabados e os conhecimentos empíricos. (Sabato, 1979).

Portanto, as máquinas, computadores, motores etc. (tecnologias entendidas como 'artefatos') podem ser disseminados de uma empresa à outra, bem como o conhecimento (codificado e tácito). Desse modo, a transferência internacional de tecnologia é o processo pelo qual uma tecnologia (artefatos ou conhecimentos codificados/tácitos) é disseminada de uma empresa estrangeira à outra (filial/subsidiária ${ }^{1}$ ou não) em território nacional por diferentes canais, de forma (in)voluntária.

Ademais, a transferência de tecnologia pode se dar de modo vertical ou horizontal. A transferência vertical ocorre quando uma tecnologia é transferida de uma empresa estrangeira para sua filial/subsidiária enquanto que a transferência horizontal ocorre quando a transferência se dá para empresas interagem com a empresa internacional, mas não são controladas por elas (como é o caso de empresas que integram redes globais de valor como fornecedoras, por exemplo). Essa separação entre transferência vertical e horizontal será retomada adiante.

A transferência internacional de tecnologia pode se dar por canais legais, mas também por canais ilegais (como contrabando, roubo, espionagem), e os principais canais utilizados são condicionados pelas características das tecnologias dominantes em diferentes momentos históricos (Chiarini, 2014).

\section{O investimento direto externo}

O IDE consiste em um 'pacote' de ativos e produtos intermediários, como capital, tecnologia, habilidades gerenciais e acesso a mercados e empreendedorismo (Dunning, 1994). Seu principal meio de inserção ocorre na forma de investimento tipo greenfield (construção de novos ativos), na forma de fusões e aquisições (F\&A) de ativos públicos e privados (já constituídos domesticamente) e na forma de investimentos 'em carteira' (aportes de capital não destinado ao controle operacional da empresa, mas às transações financeiras especulativas em mercados bursáteis). Sendo o principal indutor da internacionalização da produção, o IDE, ao menos na teoria,

\footnotetext{
${ }^{1}$ Apesar de se reconhecer a diferença jurídica entre filial e subsidiária, ambas são utilizadas como intercambiáveis no decorrer do texto, referindo-se as empresas industriais ligadas a outra (matriz ou empresa-mãe), que detém o poder de comando sobre elas.
} 
proporciona um fluxo de tecnologia para o país hospedeiro por meio das empresas transnacionais e contribui para o crescimento das exportações (Fritsch e Franco, 1989). Ademais, constitui um fluxo de informações para as empresas que se relacionam com a investidora estrangeira, sobretudo devido ao relacionamento entre elas.

O ambiente econômico de cada nação (incluindo a disponibilidade de recursos humanos e naturais, tamanho de mercado etc.) possui efeito primordial nas decisões de IDE. Por exemplo, é bastante provável que a importância das propriedades intelectuais (e de sua institucionalidade) para o IDE varie de acordo com o setor envolvido e, em particular, com a intensidade dos esforços em $P \& D$ e a propensão em (des)centralizar a P\&D, o papel tácito do conhecimento, o tipo de relação entre produtores e usuários; e o grau de concentração de mercado ${ }^{2}$. O IDE teria ao menos os seguintes papéis:

i. como forma de financiamento poderia suprir a ausência de poupança doméstica e ser uma fonte estável de financiamento externo, apoiando o crescimento doméstico (Sarti e Laplane, 2002);

ii. como forma de reestruturar o setor industrial doméstico, modernizando a estrutura organizacional e produtiva (Laplane e Sarti, 1997), aumentando a capacidade e a melhora na produtividade (Radosevic, 1999);

iii. como forma de promover a transferência internacional de tecnologia, via investimento, diminuindo o hiato tecnológico e, igualmente, promovendo o crescimento doméstico;

iv. como forma de garantir acesso a canais de comércio internacional (Laplane e Sarti, 1997);

v. como 'efeito demonstração' propiciando o processo de aprendizado (Javorcik, 2004);

vi. como forma de aumentar a demanda por produtos intermediários domésticos (o que permitiria às empresas locais se beneficiarem de economias de escala) (Javorcik, 2004);

vii. como 'efeito competição's3 (Araújo e Hiratuka, 2007).

Portanto o IDE, além de ser uma fonte de financiamento suprindo a ausência de poupança doméstica, induz efeitos multiplicadores via efeitos de encadeamento

\footnotetext{
${ }^{2}$ De acordo com Nonnenberg e Mendonça (2004), os determinantes do IDE podem ser relativos às empresas e a características dos países de origem - push factors - ou a fatores locacionais - pull factors. Os referidos autores, a partir de análises econométricas, apresentam que fatores macroeconômicos locais (tamanho e ritmo de crescimento do produto, qualificação da mão de obra, receptividade em relação ao capital externo, risco do país e desempenho das bolsas de valores) são importantes para determinar o IDE e são pouco estudados. Lim (2001) apresenta uma revisão dos principais estudos empíricos que buscaram encontrar os determinantes do IDE e conclui que o tamanho de mercado é o seu mais robusto determinante; também são importantes a infraestrutura e o nível de industrialização do país hospedeiro.

${ }^{3} \mathrm{O}$ 'efeito competição' ocorre quando as empresas domésticas buscam maior eficiência produtiva devido ao aumento da presença estrangeira no mercado nacional (Araújo; Hiratuka, 2007).
} 
(para a frente e para trás) e externalidades (positivas). Os efeitos de encadeamento estão ligados ao aumento da demanda por produtos intermediários domésticos e as externalidades (positivas) estão associadas à modernização da estrutura organizacional e produtiva, à redução do hiato tecnológico, à garantia de acesso aos mercados internacionais, ao aprendizado tecnológico e à maior eficiência produtiva das demais empresas que se encontram no mercado doméstico. Desse modo, parte das externalidades do IDE está ligada ao que Gomes (2003) e Araújo e Hiratuka (2007) chamam de 'ativos intangíveis'4 que as firmas transnacionais possuem - conhecimentos tecnológicos, habilidades organizacionais, mercadológicas e gerenciais - e com a realização do IDE há potencialidades de transbordamento e exploração dessas vantagens nos mercados dos países hospedeiros, já que as empresas estrangeiras protegem a posse desses ativos de maneira imperfeita.

\section{O IDE e a transferência de tecnologia}

A transferência de tecnologia, por meio do IDE, pode ocorrer de diferentes maneiras, e para fins analíticos se faz necessário separá-las. Portanto, a transferência de tecnologia pode ocorrer:

i. pela própria empresa estrangeira que investe domesticamente em sua filial/ subsidiária (por meio da transferência de máquinas e equipamentos importados, ou seja, por meio da tecnologia incorporada nos bens de capital);

ii. por meio do treinamento da mão de obra nas filiais/subsidiárias (ou seja, pela transferência de conhecimento tácito);

iii. pela transferência de padrões e normas de produção estabelecidos na empresa estrangeira para sua filial;

iv. pelo relacionamento com outras empresas que não são controladas diretamente pela estrangeira, mas com elas (ou com suas filiais) se relacionam por meio de uma rede;

v. pelo transbordamento a outras empresas nacionais (concorrentes, sobretudo), pelo 'efeito demonstração'.

Portanto, a transferência de tecnologia por meio do IDE pode ocorrer de forma vertical ou horizontal. A primeira refere-se às transferências pelo relacionamento entre as matrizes estrangeiras e suas filiais/subsidiárias (casos $i$, ii e iii), enquanto as últimas aos relacionamentos das filiais/subsidiárias (que receberam IDE) com outras empresas nacionais (fornecedoras, por exemplo) (casos $i v$ e $v$ ).

De acordo com Araújo e Hiratuka (2007), é mais provável que a transferência

\footnotetext{
${ }^{4}$ Os ativos podem ser entendidos como qualquer recurso ou capacidade capaz de gerar (ou contribuir para que haja) fluxos de renda futuros. São classificados em 'ativos naturais' ('frutos da terra' e trabalho não qualificado) ou 'ativos criados' (todos aqueles desenvolvidos a partir dos ativos naturais). Os 'ativos criados' são subdivididos em 'ativos tangíveis' (estoque de ativos fixos ou financeiros) ou 'ativos intangíveis' (conhecimento tecnológico, marcas, reputação, capacidade organizacional e cultura institucional) (Gomes, 2003).
} 
vertical ocorra do que a horizontal, visto que pode ser do interesse da empresa estrangeira transferir informações tecnológicas às filiais/subsidiárias a fim de aumentar a eficiência produtiva para que cumpram as exigências impostas pelo método de produção. Já a transferência horizontal é menos provável, pois se estende a outras empresas nacionais pela difusão local de conhecimento e tecnologia (ou via pressão da concorrência), ocorrendo muitas vezes de forma não intencional.

Apesar de ser mais provável, a transferência vertical não é a mais relevante, mas sim os efeitos dinâmicos da transferência tecnológica via IDE (Radosevic, 1999), os quais motivam o processo de reestruturação industrial por meio da difusão de conhecimento e da competição, rompendo com a inércia estrutural da indústria nacional. Desse modo, são os aspectos qualitativos do investimento que incorporam as novas tecnologias e o aumento do estoque de capital humano com suas externalidades para a produção doméstica que de fato importam (Mello, 1997).

Os efeitos dinâmicos estão estritamente ligados às interações entre as empresas nacionais e demais instituições, afinal, a partir de tais interações criam-se processos de aprendizado através dos quais as empresas podem aumentar suas aptidões tecnológicas e, desse modo, podem estar mais propensas a inovar. Portanto, os efeitos dinâmicos podem propiciar processos inovativos nas empresas nacionais, já que se entende a inovação como um fenômeno sistêmico e interativo, caracterizado por diferentes tipos de cooperação (Cassiolato e Lastres, 2000).

Portanto, da discussão apresentada, pode-se chegar a importantes observações:

i. IDE pode não estar ligado a investimentos na construção de novos ativos (greelfield), mas na forma de F\&A de ativos já constituídos domesticamente e na forma de investimentos 'em carteira' para fins especulativos;

ii. IDE (tipo greenfield) pode ter impacto somente vertical e pouco impacto horizontal;

iii. mesmo que o IDE esteja ligado a investimentos em novos ativos e que haja impacto horizontal significativo, a aptidão tecnológica é específica em cada firma.

\section{O INVESTIMENTO DIRETO EXTERNO E O CASO BRASILEIRO}

Uma parcela significativa do IDE mundial tem se dado via operações de F\&A ${ }^{5}$, não constituindo, portanto, operações que geram nova capacidade produtiva $(\mathrm{Ku}-$ mar, 1998; Sarti e Hiratuka, 2010). Na melhor das hipóteses, as operações de F\&A resultam em transferência de habilidades organizacionais e gerenciais (Kumar, 1998) para as empresas 'fundidas'/ 'aquisitadas', sendo, portanto, uma transferência vertical de conhecimento tácito. Esse tipo de conhecimento é de difícil disseminação

\footnotetext{
${ }^{5}$ Em 1996 foram realizadas 932 operações de F\&A, representando 16\% do total de operações neste ano e movimentando, de acordo com UNCTAD (2013), US\$ 42 bilhões. Em 2012, o volume de operações foi 2.229 (ou seja, 23\% do total de operações neste ano) e movimentou US\$ 182 bilhões.
} 
e apropriação exatamente por não ser explícito nem documentado. Exemplos de conhecimento tácito são as habilidades, competências, crenças, rotinas organizacionais e práticas.

Embora as F\&A resultem (na melhor das hipóteses) em transferência vertical de conhecimento tácito, elas permitem que as empresas nacionais tornem-se mais integradas às redes globais. Desse modo, além do conhecimento tácito, pode haver transferência de padrões e normas de produção mais modernas e congruentes com o estado da arte.

O aumento considerável do fluxo de IDE (sobretudo via F\&A) para países em desenvolvimento tem uma contrapartida não negligenciável: aumento da presença das empresas estrangeiras na estrutura produtiva e de comércio desses países (Araújo e Hiratuka, 2007), com suas estratégias elaboradas em torno de cadeias globais de valor e da exploração de oportunidades em diferentes localidades. Tais estratégias levam ao acirramento da concorrência entre as grandes massas de capitais controladas pelas grandes empresas estrangeiras, impulsionando cada vez mais o processo de internacionalização produtiva (Araújo e Hiratuka, 2007), prescindindo das estratégias de desenvolvimento nacionais.

No caso brasileiro, com o processo de abertura econômica empreendida a partir de meados dos anos 1980, delineou-se uma série de ações como a liberalização comercial e a desregulamentação das atividades econômicas no intuito de atrair maiores fluxos de IDE. Esperava-se um novo ciclo de crescimento, a partir da globalização, abertura, estabilização e privatizações (Mendonça de Barros e Goldenstein, 1997).

Tais ações contribuiriam para a promoção de padrões mais integrados da produção das corporações transnacionais no país (Bonelli, 1998) e, com o aumento da concorrência, esperava-se haver maior incentivo para que empresas nacionais aumentassem seus investimentos no desenvolvimento de produtos mais modernos e em processos de produção e gestão mais eficientes (pelo efeito competição e demonstração). ‘Naturalmente' esperava-se haver um aumento da produtividade das empresas industriais brasileiras.

Esperava-se que o fluxo de IDE, em expansão na década de $1990^{6}$ (direcionado essencialmente como resultado do processo de privatizações), conforme pode ser visto pela Figura 1, pudesse financiar o déficit em transações correntes e aumentar as exportações industriais brasileiras 7 (Medeiros, 1997; Sarti e Laplane,

\footnotetext{
${ }^{6}$ Não é objetivo deste estudo apresentar uma análise exaustiva sobre a abertura comercial e IDE no Brasil nos anos 1990. Para uma revisão crítica sobre a temática ver, por exemplo, Gonçalves (2003), o qual destaca os principais pontos do processo de internacionalização da economia brasileira, que ganhou força na década de 1990, situando o debate em torno dos seus dois elementos principais: a liberalização comercial e o crescimento da participação de empresas estrangeiras na economia brasileira.

${ }^{7} \mathrm{O}$ impacto dos fluxos de IDE na Balança de Pagamentos depende da finalidade do IDE, ou seja, da natureza da atividade a qual o IDE é destinado (por exemplo, IDE direcionado para setores tradables versus non-tradables). Os resultados finais são ambíguos, na medida em que o comércio externo deve ser levado em consideração. Alguns impactos resultam em aumento das exportações, enquanto outros
} 
2002). Esperava-se ainda que a abertura empreendida pudesse mobilizar esforços inovativos e tecnológicos das empresas estrangeiras, o que contribuiria para uma mudança estrutural da economia brasileira, reduzindo o déficit comercial por meio das exportações de elevado valor agregado e alto conteúdo tecnológico.

Figura 1 - Fluxo de IDE (milhões US\$) e IDE como proporção do PIB (\%) Brasil, 1990-2009

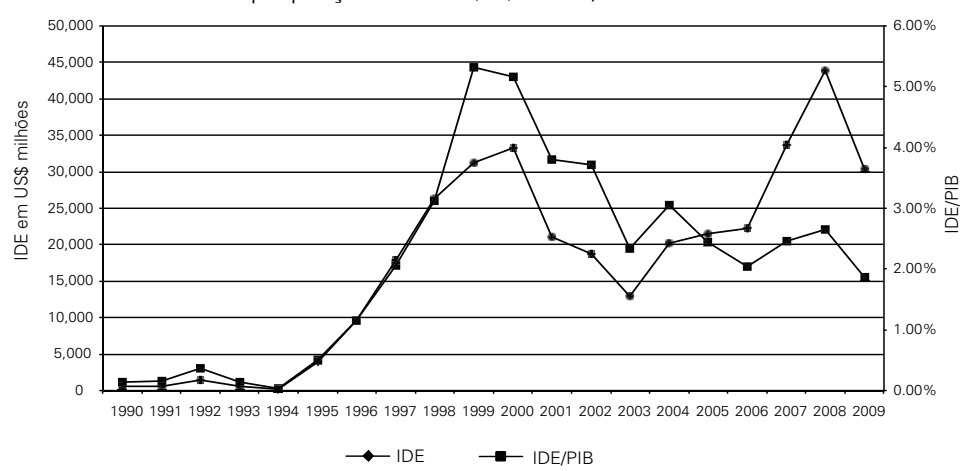

Fonte: Elaboração própria a partir dos dados do Departamento de Capitais Estrangeiros e Câmbio do Banco Central do Brasil para o IDE e da Seção de Atividade Econômica do Boletim do Banco Central do Brasil (BCB Boletim/Ativ. Ec.) para o PIB (PIB - câmbio médio). Os dados sobre IDE de 1990-95 foram calculados por Laplane e Sarti (1997). OBS: As médias por período (em milhões) são: 1990-94: US\$688,36; 1994-99: US\$14.870,13; 1990-99: 9.247,44; 1990-09: US\$ 17.529,04; 2000-09: US\$25.810,65.

Entretanto, conforme apontam Cassiolato e Lastres (2014), o IDE estava em grande parte voltado para a exploração das oportunidades oferecidas pelo mercado interno (incluindo o Mercosul) via, basicamente, F\&A de empresas brasileiras, tendo se realizado pouco investimento (tipo greelfield). Ademais, Cassiolato e Zapiro (2015) sugerem que, no contexto da desregulamentação e liberalização da economia a partir dos anos 1990, houve uma desarticulação de vários sistemas produtivos e inovativos e capacitações produtivas foram destruídas. Houve um crescente aumento do déficit comercial brasileiro no setor de alto conteúdo tecnológico (Figura 2), saindo de um déficit de US\$ 8.380,25 milhões em 1996 para US\$ $31.118,00$ milhões em 2012, isto é, uma taxa de $73 \%$ no período.

O IDE na década de 1990 estava fortemente relacionado com uma simples mudança patrimonial, concentrada em F\&A de ativos locais das empresas estatais do setor de serviços recém-privatizadas (como telecomunicações, por exemplo) (Cassiolato et al., 2014). Miranda (2001) constata que, das 1.149 operações efetuadas no período 1991-99 no Brasil, quase 60\% foram de aquisições de empresas privadas (domésticas ou estrangeiras) por transnacionais; aproximadamente $3 \%$ foram aquisições de empresas estatais por consórcios estrangeiros; aproximada-

podem implicar considerável crescimento das importações na forma de bens de capital, peças e componentes, pelo menos por algum período. Os efeitos indiretos na Balança de Pagamentos são ainda mais difíceis de serem avaliados (Bonelli, 1998). 
Figura 2 - Saldo comercial brasileiro dos setores industriais por intensidade tecnológica, US\$ milhões, 1996-2012

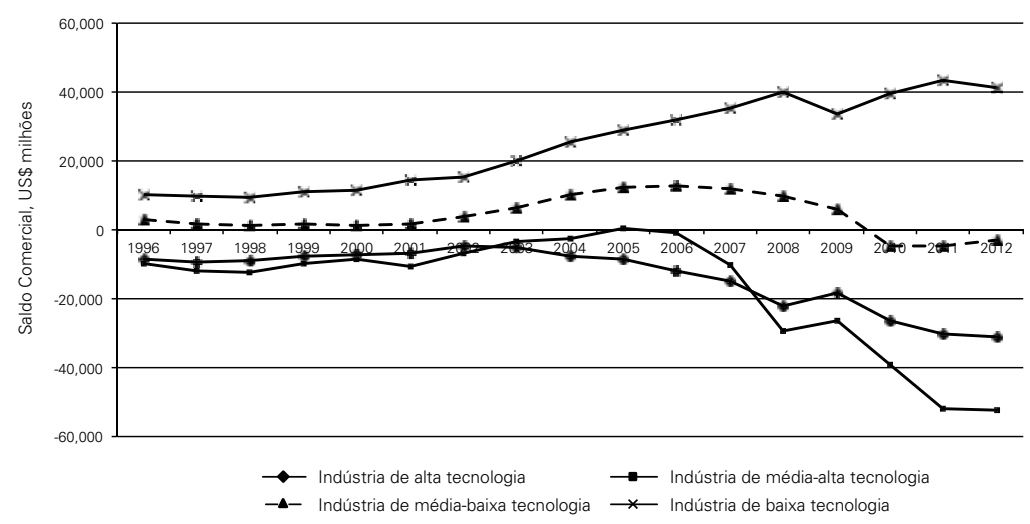

Fonte: Elaboração própria a partir dos dados compilados pela SECEX/MDIC. Nota: valor FOB. Classificação extraída de OECD, Directorate for Science, Technology and Industry, STAN Indicators, 2003.

mente $30 \%$ foram aquisições de empresas brasileiras por outras empresas nacionais; $4 \%$ foram adquiridas por consórcios nacionais e quase $2 \%$ por consórcios mistos. Vale mais uma vez mencionar que IDE com vistas às F\&A, na melhor das hipóteses, propicia apenas transferência de habilidades gerenciais e organizacionais (Kumar, 1998).

De acordo com Negri (2007) as políticas brasileiras de atração do IDE não tiveram requisitos relacionados ao desenvolvimento doméstico de tecnologia por parte das multinacionais. Ao contrário, o Brasil adotou o entendimento que a simples presença estrangeira seria capaz de dinamizar a estrutura produtiva nacional e contribuir para a produção local de tecnologia, utilizando-se de uma política do tipo 'portas abertas' (Negri, 2007).

A média do fluxo de IDE no Brasil, no período de 1990-99, foi US\$ 9.247,44 milhões, sendo que no primeiro subperíodo (1990-94) o fluxo foi inferior ao segundo subperíodo (1994-99) (Figura 1). A década de 1990 marca um fluxo de IDE para o Brasil ainda não tão elevado (vis-à-vis a década seguinte), mas em crescente expansão. De acordo com Bonelli (1998), a mudança na legislação concernente aos fluxos de capitais foi responsável pelo sucesso do país em atrair IDE ${ }^{8}$.

A Figura 1 mostra a evolução do fluxo do IDE em toda a década de 1990 (eixo da ordenada à esquerda). Muito embora a média do fluxo fosse relativamente elevada para os padrões da época, Laplane e Sarti (1997) sugerem que o poder

\footnotetext{
${ }^{8}$ Ademais, as estratégias das grandes corporações transnacionais também são importantes para entender o aumento do fluxo de IDE para o Brasil no período. Não somente a mudança na legislação brasileira, uma política econômica amigável ao capital estrangeiro e o tamanho do seu mercado podem ter atraído grande parte de IDE, mas fatores externos também são importantes neste contexto. Por exemplo, crises financeiras em algumas regiões podem fazer com que as transnacionais direcionem recursos para outras regiões.
} 
de indução do IDE foi baixo no período, o que quer dizer que as fragilidades estruturais da economia brasileira fizeram com que parte do impulso dinâmico dos investimentos fosse direcionada para o exterior, alimentando a importação de máquinas, equipamentos e tecnologias produzidas no estrangeiro. Por exemplo, a quantidade de bens de capital importados foi sempre inferior à quantidade de bens de capital produzidos domesticamente para fins industriais, no entanto, a quantidade de bens de capital importados teve tendência crescente, sobretudo a partir de 2007, o quantum importado de bens de capital passa a ser superior à produção doméstica de bens de capital (Figura 3). Essas evidências corroboram a dependência da indústria brasileira por máquinas e equipamentos externos.

As políticas macroeconômicas de estabilização adotadas (câmbio real valorizado e juros reais elevados) na década de 1990 foram inicialmente relevantes como fatores de atração do IDE, e o processo de F\&A (via privatizações) adquiriu importância (Carneiro, 2002). Os fluxos de IDE exibiram novo impulso a partir de 1992, inicialmente sob a forma de carteira de investimentos, atraídos por diferenciais de taxas de juros reais elevados, devido à alta de juros pagos sobre a dívida pública (Bonelli, 1998). Os anos 1990 marcaram picos históricos da entrada de fluxo de IDE e de IDE como proporção do PIB, se comparados com períodos anteriores à abertura econômica.

Laplane e Sarti (1997) sugerem que na década de 1990 o IDE provocou expressivo aumento da eficiência e da competitividade de setores relativamente defasados em relação aos padrões internacionais, porém o principal instrumento utilizado foi a importação pesada de componentes e de tecnologia, sem a contrapartida equivalente no aumento das exportações de produtos com alto teor tecnológico (Figura 2).

A Figura 1 permite inferir que o Brasil estava se apoiando cada vez mais no capital externo para garantir seu crescimento. Os anos 2000 apresentaram um fluxo de IDE superior ao da década anterior. No período 2000-09 a média de entradas foi US\$ 25.810,65 milhões, ou seja, 2,79 vezes superior à média da década de 1990.

Embora o Brasil tenha recebido elevados volumes de IDE durante o período em análise, conforme apresentado, apenas uma parte contribuiu diretamente para o aumento da capacidade produtiva. A Figura 4 mostra uma comparação dos fluxos de IDE com a formação bruta de capital fixo (FBKF) e dos fluxos de IDE para o setor industrial com a FBKF.

O fluxo de IDE como proporção da FBKF cresceu consideravelmente a partir de 1994 e manteve-se com este perfil de crescimento até 1999. O fluxo de IDE para o setor industrial como proporção da FBKF manteve ligeira tendência de crescimento, embora represente pouco como proporção da FBKF, sugerindo que o IDE para a indústria tem contribuído relativamente pouco para o aumento da taxa de investimento (medida pela FBKF) na economia brasileira.

A principal razão para a baixa contribuição do IDE em geral (e do IDE industrial em particular) para a taxa de investimento parece estar associada às características assumidas pelos fluxos de IDE recebidos. Conforme já assinalado, parte 
Figura 3 - Quantum-índice da produção doméstica de bens de capital para fins industriais e quantum-índice da importação de bens e capital, Brasil, 1990-2012

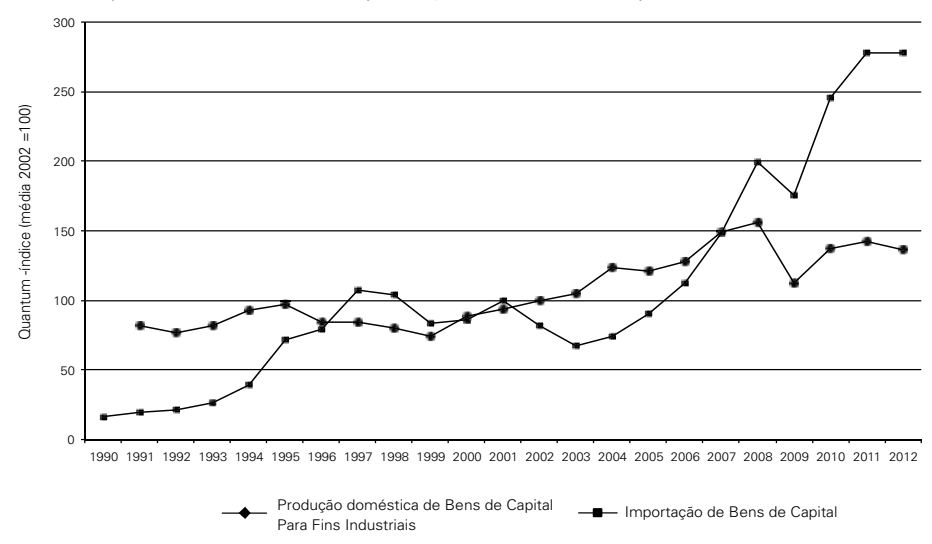

Fonte: Elaboração própria a partir dos dados da Fundação Centro de Estudos do Comércio Exterior (Funcex) e Diretoria de Pesquisas, Coordenação de Indústria do IBGE. Nota: base $2002=100$

significativa do IDE (especialmente nos anos 1990) destinou-se à aquisição de ativos preexistentes, a partir de F\&A. Em tais casos não se pode esperar qualquer efeito sobre o crescimento da FBKF, a não ser que os novos proprietários das empresas adquiridas realizem investimentos adicionais - seja na modernização das plantas, seja em ampliação da capacidade produtiva (o que não foi o caso) (Gonçalves, 2003).

Figura 4 - IDE como proporção da FBKF e IDE para a Indústria como proporção da FBKF, Brasil, 1990-2009

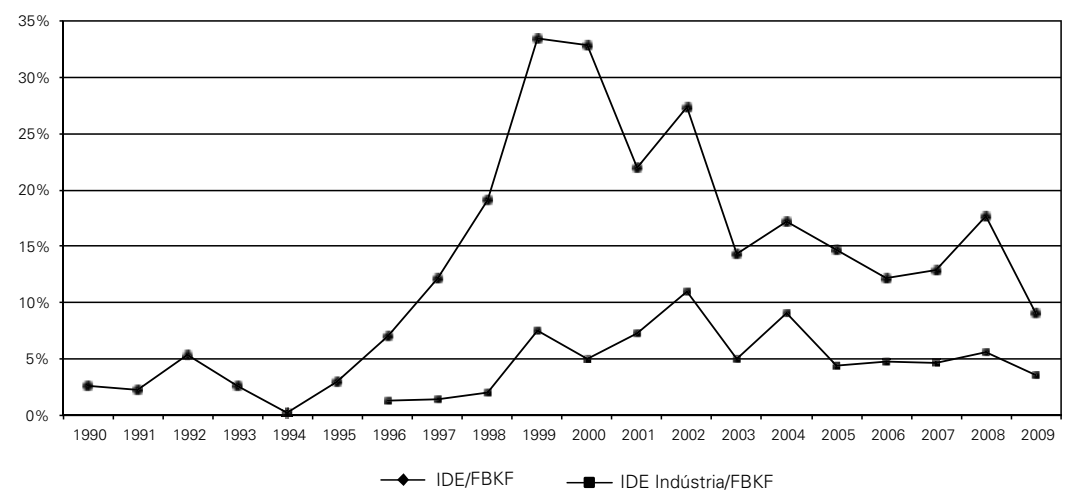

Fonte: Elaboração própria a partir dos dados do Departamento de Capitais Estrangeiros e Câmbio do Banco Central do Brasil para o IDE e para a FBKF utilizou-se de dados compilados pelo IPEAdata do Instituto Brasileiro de Geografia e Estatística, Sistema de Contas Nacionais, a qual foi convertida em US\$ pela 'Taxa de Câmbio Comercial para Compra', compilada pelo IPEAdata a partir dos dados do Banco Central do Brasil, Boletim, Seção Balanço de Pagamentos (BCB Boletim/BP). Os dados sobre IDE de 1990-95 foram calculados por Laplane e Sarti (1997). 
Pelo exposto, o elevado influxo de IDE para o Brasil deve ser visto com cautela: por um lado, ele melhorou a capacidade produtiva do país, mas por outro aumentou a dependência de capital estrangeiro. Dados sobre a década de 1990 revelam que a entrada maciça de IDE no Brasil após o processo de abertura não garantiu que a mesma fosse acompanhada pelo desenvolvimento doméstico de tecnologias de fronteira que significasse maior inserção de produtos com alto conteúdo tecnológicos brasileiros no mercado internacional.

Figura 5 - Distribuição do fluxo de IDE por atividade econômica de aplicação dos recursos, \%, Brasil, 1996-2009

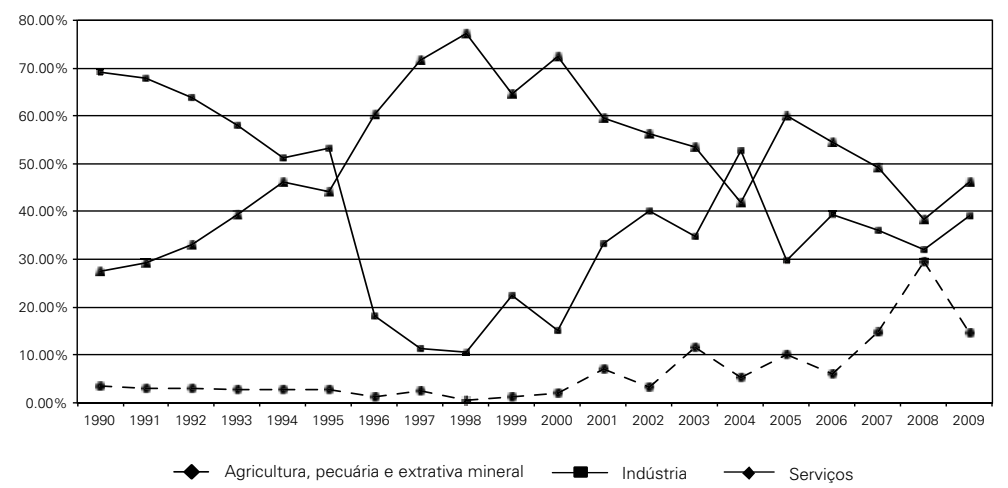

Fonte: Elaboração própria a partir dos dados do Departamento de Capitais Estrangeiros e Câmbio do Banco Central do Brasil. Nota: 1) os dados de 1995 referem-se ao somatório até junho do referido ano; 2) no período 1996-2000 o somatório das distribuições por atividade econômica de aplicação dos recursos não totaliza 100\%, uma vez que nesse período, consideram-se somente os recursos destinados às empresas que totalizaram mais de US\$10 miIhões /ano, assim, os ingressos abaixo de US\$10 milhões por empresa receptora/ano não foram distribuídos por atividade econômica.

Analisando o IDE por atividade econômica de aplicação dos recursos tem-se que, de 1996 a 2003, o maior percentual de IDE foi destinado ao setor de serviços, o qual é menos intensivo em tecnologia do que o setor industrial (Kumar, 1998).

Em 2000 o IDE para indústria foi de 15\% e em 2009 foi de 39\% (Figura 5). Verifica-se, portanto, um aumento de IDE para a indústria e uma queda do IDE para serviços (explicado em parte pelo fim das privatizações de empresas de serviços de telecomunicações).

A média do fluxo de IDE para a indústria no período 1996-99 foi de US\$ 3.386,31 milhões. Nos anos 2000 há um crescimento do IDE para a indústria, sendo que no período 2000-09 a média foi de US\$ 8.809 milhões (Figura 5).

Interessante destacar que a presença de capital estrangeiro na indústria brasileira implicou uma concentração em alguns setores industriais. O fluxo de IDE na década de 1990 concentrou-se basicamente na indústria de produtos químicos, metalurgia básica, indústria eletrônica e de comunicação e indústria. No período 199699 a indústria química concentrou em média $15 \%$ de todo IDE para a indústria de transformação e a indústria de fabricação e montagem de veículos automotores, $23 \%$. 


\section{A PROPOSIÇÃO DA FALTA DE APTIDÃO TECNOLÓGICA}

O comportamento das empresas está intimamente ligado às suas aptidões e como elas evoluem com o desenvolvimento do setor a qual pertencem, juntamente com a tecnologia, comportamento da demanda e as instituições. A abordagem evolucionária sugere que as empresas possuem aptidões específicas as quais, na maior parte das vezes, possuem natureza tácita e estão incorporadas em 'rotinas'. $O$ processo pelo qual a aprendizagem e as rotinas são desenvolvidas, em grande medida, é específico a cada empresa e historicamente dependente (path dependent) (Malerba e Orsenigo, 1993; Teece e Pisano, 1994).

As estratégias das empresas são, portanto, afetadas pelos seus tipos e níveis de aptidões. De forma geral, as aptidões são um conjunto específico de competências (tecnológicas, inventivas, design etc.) e formam ativos complementares de uma dada empresa. As competências definem, portanto, o que uma empresa pode fazer, moldam sua estrutura organizacional e limitam as escolhas possíveis (Malerba e Orsenigo, 1993).

A noção de aptidão tecnológica, portanto, é uma tentativa de capturar a grande variedade de conhecimentos (tácitos e codificados) e competências necessários para adquirir, assimilar, usar, adaptar, modificar e criar tecnologia (Radosevic, 1999). A aptidão tecnológica permite às empresas identificar o valor de novas informações externas, assegurar seu poder de barganha nas negociações de transferência de tecnologia, assimilar o conhecimento transferido e deixá-la mais sensível às novas oportunidades tecnológicas (Kim, 2005 [1997]). Provém de um processo ativo de aprendizado caracterizado pela sua lentidão, cumulatividade e especificidade às firmas e às áreas de conhecimento (Malerba e Orsenigo, 1993; Lall, 2004). Processo esse que não é automático; carece de investimentos, envolve o domínio e a mudança de rotinas corriqueiras em processos mais intensivos em conhecimento (Bessant et al., 1999).

O aprendizado, por sua vez, é um processo de mudança técnica, ativado pela difusão e criação de inovações incrementais, ou seja, o aprendizado é a absorção de tecnologias existentes (absorção de invenções produzidas em outras nações) e a geração de melhoras ao se utilizar tais tecnologias (Viotti, 2002).

A aptidão tecnológica (que não é genérica), de acordo com Kim (2005), pode ser construída e fomentada por meio:

i. da comunidade internacional (informações incorporadas no equipamento, informações incorporadas no indivíduo, informações impressas, fornecedores estrangeiros, compradores estrangeiros);

ii. da comunidade nacional (universidades, institutos de pesquisa, outras empresas, outros sistemas de apoio); e

iii. dos esforços internos das empresas (treinamento interno, P\&D, produção).

Nessa esteira, o IDE (canal típico de transferência de tecnologia, conforme já discutido) pode gerar oportunidade para ampliar as aptidões tecnológicas. Desse modo, a análise da falta de eficácia do IDE (especial do tipo greenfield) como canal 
de transferência de tecnologia pode ser feita de acordo com o caráter vertical ou horizontal da transferência:

i. quando a transferência ocorre pela própria empresa estrangeira que investe domesticamente em sua filial/subsidiária; por meio da transferência de máquinas e equipamentos importados, quando ocorre por meio do treinamento da mão de obra nas filiais/subsidiárias; por meio de padrões e normas de produção estabelecidos na empresa estrangeira para sua filial: portanto, gera-se um processo de aprendizado para a empresa filial/subsidária e, portanto, há uma forma passiva de absorção do novo conhecimento (Viotti, 2002);

ii. quando a transferência ocorre pelo relacionamento com outras empresas que não são controladas diretamente pela estrangeira, mas com elas (ou com suas filiais/subsidiárias) se relacionam por meio de uma rede e pelo transbordamento a outras empresas nacionais (concorrentes, sobretudo), pelo 'efeito demonstração': gera-se um processo de aprendizado para demais empresas por meio de um processo ativo de absorção do novo conhecimento (Viotti, 2002), resultante de esforços deliberados para que o mesmo ocorra. Assim, a imitação e a engenharia reserva produzem um maior entendimento das tecnologias transferidas e geram maiores oportunidades para inovações.

Em ambos os casos é preciso um nível de aptidão tecnológica mínimo que somente se alcança com uma base científica e técnica nacional bem estruturada (Carrere, 2011 [1975]). Desse modo, a aptidão tecnológica é pressuposto básico para que eventuais oportunidades tecnológicas sejam aproveitadas (Albuquerque, 1998). Portanto, outras categorias de aptidão também são relevantes para o entendimento do processo de aprendizado e da transferência de tecnologia: i) aptidão organizacional; ii) administração das ligações entre diferentes tipos de instituições envolvidas no processo de transferência (Bruland, 1998); e iii) 'aptidão científica'.

A proposição da falta de aptidão tecnológica das empresas industriais brasileiras encontra raízes históricas no próprio processo de industrialização por substituição de importações, o que não constituiu as condições para a necessária internalização de capacidades inovativas (Paula, 2005; Sarti e Hiratuka, 2010), ao mesmo tempo em que já se colocava em curso uma nova onda de inovações tecnológicas baseadas nas TICs, novos materiais e na biotecnologia, gestando um novo paradigma tecnológico (Paula, 2005).

\footnotetext{
${ }^{9}$ A ciência tem papel importante em nações em processo de emparelhamento, pois ajuda a identificar as oportunidades geradas no exterior. Ademais, para estas nações a ciência funciona como antena para a criação de links com fontes internacionais de tecnologia e coloca o SNI nos fluxos científicos e tecnológicos internacionais. A emergência de uma economia baseada no conhecimento aumenta a importância dessa contribuição para a criação de capacidade de absorção (chave para o processo de emparelhamento, conforme já apresentado) (Albuquerque, 2001).
} 
A trajetória de industrialização por substituição de importações ${ }^{10}$ usou o potencial de crescimento do mercado interno e pouca ênfase foi dada à capacidade de competir globalmente. O foco nas exportações quase sempre foi de natureza emergencial, para sanar problemas no balanço de pagamentos (Pacheco e Almeida, 2013). Tal ênfase 'cristalizou-se' na cultura industrial brasileira e, até hoje, a inserção internacional da indústria nacional é frágil.

Desde os anos 1950, as importações brasileiras de tecnologias estavam tipicamente desconexas das atividades inovativas significantes nas empresas que as importavam (Bell e Cassiolato, 1993; Radosevic, 1999). Os esforços de tecnologia não estavam direcionados para a melhor fronteira prática, mas para a obtenção de tecnologias para ajustá-la às condições locais (Radosevic, 1999). Desse modo, como consequência, as tecnologias importadas tinham pouco alcance no processo de assimilação no contexto de rápida mudança tecnológica.

A via de desenvolvimento baseado na política de 'boas-vindas' às transnacionais gerou a possibilidade de que as empresas estrangeiras (e também as locais) prescindissem da necessidade de vinculação com instituições locais de C\&T, já que se apostava nas tecnologias e conhecimentos produzidos fora do território nacional (Thomas et al., 1997). A política de atração de empresas estrangeiras foi possível a partir da proteção do mercado doméstico e um conjunto de subsídios e tratamento especial ao investidor estrangeiro também foram utilizados como elementos estratégicos para incentivar empresas a se estabeleceram no Brasil (Dahlman e Frischtak, 1990).

A falta de concorrência externa gerou pouca 'ânsia' por competir globalmente, o que implicou a desnecessidade de inovar constantemente, o que reflete a baixa tradição inovadora das empresas. Portanto, determinou-se uma situação caracterizada por produtividade, qualidade e competitividade dos produtos e processos locais inferiores à média mundial (Dagnino, Thomas e Davyt, 1996).

Cabe ressaltar que, no período de industrialização por substituição de importações, não houve uma formulação estratégica com implementação de uma política clara que buscasse deliberadamente a absorção social do conhecimento produtivo, com o conseguinte processo de aprendizagem industrial e tecnológico, o que

${ }^{10}$ Pela própria natureza do processo de industrialização por substituição de importações, trata-se de processo de desenvolvimento interno originário de restrições externas que se manifesta, primordialmente, pela ampliação e diversificação da capacidade produtiva industrial (Tavares, 1981). De acordo com Tavares (1981, p. 41) "a dinâmica do processo de desenvolvimento pela via de substituição de importações pode atribuir-se, em síntese, a uma série de respostas aos sucessivos desafios colocados pelo estrangulamento do setor externo, através dos quais a economia vai-se tornando quantitativamente menos dependente do exterior e mudando qualitativamente a natureza dessa dependência”. O modelo de industrialização por substituição de importações significou a criação de filiais isoladas que se submeteram a escalas e tecnologias consistentes com a existência de mercados fortemente protegidos e transações internacionais fortemente reguladas. A política vigente induziu em geral uma relação passiva destas filiais com suas fontes de abastecimento de bens de capital, insumos e tecnologias e mostraram pouca articulação com o setor empresarial doméstico (Vera-Vassallo, 1996). 
comprometeu, no longo prazo, uma inserção internacional mais dinâmica e de qualidade superior (Vera-Vassallo, 1996).

Foi dada ênfase ao papel das empresas estatais e dos laboratórios de pesquisa públicos, enquanto ao setor privado doméstico, não foi dada significância no processo inovativo, cujos esforços se limitavam à adaptação de produtos e processos e dependiam da importação de máquinas e equipamentos ou de 'efeitos de transbordamento' das empresas estatais ou das transnacionais (Katz, 2000).

O padrão de industrialização, com elevada proteção da economia, não resultou em processo de aprendizado, ou na melhor das hipóteses resultou em aprendizado parcial. O protecionismo adotado foi um 'protecionismo frívolo', o qual não favoreceu um processo de aprendizado liderado por grupos nacionais. A proteção nunca esteve a serviço de uma estratégia concebida por agentes domésticos e orientada para a conquista futura do mercado internacional (Fajnzylber, 1983).

Não houve o desenvolvimento de um processo de aprendizado ativo (Viotti, 2002). A política de atração de IDE visava dar um salto rumo à modernidade industrial de ramos industriais específicos, sendo relegada a segundo plano a importância da aquisição e do estímulo de construção de aptidão tecnológica doméstica para o processo de industrialização e para balanço de pagamentos. Uma combinação de esforços tecnológicos nacionais fracos e acesso restritivo à tecnologia estrangeira parece ter dificultado esforços de modernização das empresas industriais brasileiras (Dahlman e Frischtak, 1990).

Embora o setor produtivo, submetido a uma lógica econômica de importação de tecnologia, não tenha internalizado uma dinâmica de geração endógena de tecnologia significativa, não se pode afirmar que não houve qualquer tipo de aprendizado: havia adequação, embora não fosse a regra, de tecnologias importadas às condições locais, o que implicou, em alguns casos, a realização de modificações ou inovações menores (incrementais), buscando realizar ajustes de escalas, diferenças nos insumos ou condicionantes de uso dos bens produzidos. Gerou-se um processo de aprendizado tecnológico importante, porém muito limitado (Dagnino, Thomas e Davyt, 1996).

Durante os anos 1980, o parque industrial brasileiro não avançou em termos de modernização e investimentos, iniciando a década de 1990 com o mesmo perfil herdado dos anos 1970, quanto havia completado a estrutura industrial típica da Segunda Revolução Industrial (Muniz, 2000), sendo esse o principal legado do período de industrialização por substituição de importações (Vera-Vassallo, 1996). Porém, uma indústria que não investe se torna progressivamente obsoleta, não cresce e tem dificuldades de assimilar progresso técnico; portanto, perde produtividade, novas oportunidades e competitividade (Cano, 2012). Foi exatamente o que aconteceu no Brasil.

Esta situação assume caráter crítico quando se percebe que o parque industrial brasileiro pouco se modernizou em um período em que o mundo exibia uma aceleração notável em termos de desenvolvimento tecnológico, enquanto no Brasil características do período da industrialização por substituição de importações foram 'cristalizadas' (como a falta de diálogo entre a pesquisa pública e o setor pro- 
dutivo privado). Foi esse parque industrial (obsoleto) que foi submetido à disciplina da concorrência externa, quando a economia foi aberta e os empresários letárgicos foram expostos aos ares da globalização (Belluzzo, 2013).

Desse modo, o período pode ser caracterizado pela presença de equipamentos e bens de capital antiquados, métodos de produção obsoletos e modalidades deficientes de gestão e organização empresarial se comparados às nações centrais, além de uma fraca relação entre empresas e universidades/institutos públicos de pesquisa.

\section{COMENTÁRIOS}

Os fluxos de IDE devem ser entendidos de uma maneira mais ampla e crítica, integrados às estratégias globais das grandes corporações transnacionais, as quais são arquitetadas em torno de cadeias globais de valor e da exploração de oportunidades em diferentes localidades (para valorização do capital, seja de forma produtiva ou fictícia).

Contrariamente ao que acontecera no passado, quando o IDE era portador de novas tecnologias (de produtos ou processos), na atual fase do capitalismo ele significa principalmente a aquisição de ativos já existentes (Carneiro, 2002, 2007), reduzindo o seu papel de mecanismo de transferência internacional de tecnologia. Assim, a fragmentação do processo de produção e o desenvolvimento de redes complexas de suprimento permitem às corporações transnacionais maior controle e flexibilidade para designar onde (quando e como) investir e seus ativos produtivos (a saber, know-how, design e tecnologia) podem ser salvaguardados no interior das empresas de forma mais segura (Akyuz, 2005). Horizontalmente, formam-se alianças estratégicas entre empresas do mesmo core produtivo (cujo fim é compartilhar custos elevados de $\mathrm{P} \& \mathrm{D})$ e, no âmbito vertical, amplia-se o regime de sourcing (subcontratação) com estreitamento das relações monitoradas na cadeia produtiva, dada a relevância das especificações tecnológicas (Carneiro, 2007).

As grandes corporações transnacionais, detentoras de tecnologia, exploram suas vantagens de quase monopólio em mercados de economias menos desenvolvidas. Essas vantagens podem ser exploradas diretamente com o estabelecimento de subsidiárias no exterior (com IDE greenfield) ou podem ser compartilhadas com empresas já estabelecidas nas economias menos desenvolvidas por meio de contratos de licenciamento, por exemplo (Cooper, 1972). Em muitos casos, o processo de F\&A (e a fragmentação da produção em redes de fornecedores) implicou a descontinuação de centros de P\&D das empresas que foram adquiridas (ou mesmo daquelas que existiam em algumas subsidiárias), as quais passaram a ocupar-se apenas da 'tropicalização' da tecnologia (ou seja, da adaptação da tecnologia da matriz às condições locais) (Ricupero, 2014).

O IDE como canal de transferência internacional de tecnologia pode não cumprir seus efeitos esperados. A presença das empresas transnacionais pode ter impactos negativos, em particular quando desloca empresas nacionais, reduzindo seu market share, especialmente para segmentos de mercados menos favoráveis e com 
menor potencial de rentabilidade, sendo este um transbordamento negativo nos encadeamentos horizontais.

Há também efeitos negativos nos encadeamentos verticais, como, por exemplo, a substituição dos fornecedores domésticos por fornecedores estrangeiros que façam parte da rede global de fornecimento à transnacional, causando um deslocamento das empresas nacionais (Araújo e Hiratuka, 2007).

No caso brasileiro, grande parte do IDE foi direcionado a setores que não o industrial (non-tradables). O efeito provável de demonstração, observação, imitação e aplicação de tecnologias avançadas implementadas domesticamente pelos fluxos de IDE deve ser relativizado. Verifica-se que do fluxo de IDE para o setor industrial ficou concentrado em algumas indústrias, como a indústria automobilística (nos anos 2000, pelo apoio governamental explícito ao setor). Vale ressaltar ainda que nem todos os setores industriais são capazes de difundir conhecimento na mesma intensidade (Cimoli et al., 2005) e mesmo que fossem, nem todas as empresas domésticas são homogêneas no que se refere ao grau acumulado de aptidões tecnológicas, o que implica que possíveis efeitos de transbordamento positivo gerados pelo IDE podem não ser absorvidos (Araújo e Hiratuka, 2007).

Ademais, cumpre destacar que a produção de conhecimento (concentrada em poucas nações) é centralizada em poucas corporações transnacionais (Negri, 2007). Para que as empresas estrangeiras cumpram, de fato, um papel ativo na transferência internacional de tecnologia via IDE, é necessário que existam condições apropriadas para a realização de atividades tecnológicas e aptidões tecnológicas nas nações receptoras (Negri, 2007).

As grandes corporações transnacionais (com suas estratégias de fragmentação da produção) desempenham um papel relevante para a transferência internacional de tecnologia e se as atividades de IDE ocorrem basicamente entre matrizes multinacionais e suas filiais, então se produz uma transferência intrafirmas de tecnologia e a absorção e a difusão para o restante do setor produtivo doméstico são limitadas (Vera-Vassallo, 1996; Kumar, 1998).

Nesse cenário, o IDE proporciona um processo de 'aprendizado parcial' (Erber, 2014), possibilitando transbordamento limitado para as demais firmas na cadeia produtiva. O chamado transbordamento horizontal ocorre para as empresas concorrentes e é pouco provável que aconteça neste contexto.

No entanto, pode-se esperar um transbordamento vertical, isto é, por meio das relações intersetoriais (via mercados de insumo e produtos e pelos encadeamentos produtivos), embora de amplitude limitada, já que, no caso brasileiro, reconhece-se que as filiais brasileiras das transnacionais são mais integradas ao mercado internacional do que ao doméstico (sem que isto reflita em resultado comercial favorável ao Brasil) (Negri, 2003). De acordo com Cassiolato e Lastres (2005), o Brasil representa um paradoxo: importante receptor de IDE e pouco importante objeto de gastos em P\&D por parte das subsidiárias.

Pode-se afirmar que as empresas estrangeiras no Brasil possuem mecanismos efetivos de proteção de seus ativos intangíveis e que as empresas nacionais pouco se beneficiam dos efeitos de transbordamento. Desde modo, o fluxo de IDE para o 
Brasil não resultou em mudanças estruturais na base produtiva nacional e não foi bem-sucedido em motivar os esforços tecnológicos e inovativos como se esperava (Cassiolato et al., 2014).

Transferir tecnologia demanda tempo e recursos e pode não significar que o seu efetivo uso ocorrerá de imediato. Não se pode simplesmente importá-la dos países líderes, já que, quando ela for introduzida e assimilada de forma eficiente, os líderes já terão avançado sua posição relativa (moving target). Por ser um sistema dinâmico, tanto a inovação quanto o ambiente econômico mudam enquanto a difusão de tecnologia ocorre e investimentos passados (em velhas tecnologias estabelecidas) podem dificultar a difusão de novas tecnologias (Soete, 1985). Configura-se assim a dependência das trajetórias históricas (path dependence).

Não somente o aprendizado formal, mas também o aprendizado informal é valoroso para diversos casos bem-sucedidos de emparelhamento, pois essencialmente ajudam a construir e aprimorar as aptidões tecnológicas. Um elevado nível educacional e um elevado nível de confiança (capital social) para o aprendizado informal é necessário, ou seja, o grau de confiança na sociedade e os valores do sistema educacional são itens informais considerados na definição 'ampla' de um Sistema Nacional de Inovação - SNI (Lundvall et al., 2009). Em outros termos, o aprendizado (formal ou informal) é elemento importante à aptidão tecnológica, já que é adquirida via processo de aprendizagem tecnológica.

Obter tecnologias e operá-las adequadamente geralmente requer um processo de learning-by-doing, por parte de engenheiros e gerentes para operarem as máquinas importadas, bem como requer investimentos em instalações e demais equipamentos auxiliares. Assim, a transferência internacional de tecnologia, a partir dos exemplos históricos apresentados, envolveu muito mais do que o conhecimento corporificado em algumas pessoas, ou alguns desenhos e modelos. Estes podem fornecer um começo rumo ao emparelhamento tecnológico, mas o comando real da tecnologia requer uma quantidade considerável de aprendizagem organizacional (tentativa e erro) (Nelson e Wright, 1992), a qual é local e historicamente dependente (path-dependent) (Malerba e Orsenigo, 1993).

Ademais, existem vínculos que não são estabelecidos pelo mercado, mas por outros fatores, como pelo capital social, educação, política e sentimentos nacionais de um povo (Silveira, 2001; Putman, 2005). Existem diferenças marcantes entre nações sobre como o processo de aprendizado ocorre, em termos institucionais e organizacionais, e isso possui implicações não menosprezáveis para a história do desenvolvimento das nações (Bruland, 1998).

A transferência internacional de tecnologia requer um aparato institucional capaz de explorar as oportunidades tecnológicas (potencialidade das inovações e dos aperfeiçoamentos) disponíveis internacionalmente e que as complemente com uma acumulação tecnológica doméstica (Radosevic, 1999). O exposto sugere que tanto o processo de transferência internacional de tecnologia quanto o contexto em que ocorrem são relevantes na compreensão do porquê algumas nações terem feito bom uso das oportunidades externas e outras não. Ademais, as oportunidades 
tecnológicas são dinâmicas e ajudam a moldar o sistema econômico; assim, respostas a elas devem acompanhar tal dinâmica.

\section{REFERÊNCIAS}

AKYUZ, Y. (2005) “Impasses do desenvolvimento”. Novos Estudos CEBRAP, v. 72, p. 41-58.

ALBUQUERQUE, E. M. (1998) "Patentes segundo a abordagem neo-schumpeteriana: uma discussão introdutória”. Revista de Economia Política, v. 18, n. 4, p. 65-83.

ALBUQUERQUE, E. M. (2001) "Scientific infrastructure and catching-up process: notes about a relationship illustrated by science and technology statistics". Revista Brasileira de Economia, v. 55, n. 4, p. 545-566.

ARAÚJO, R. D.; HIRATUKA, C. (2007) "Exportações das firmas domésticas e influência das firmas transnacionais”. In: (rrgs.). As Empresas Brasileiras e o Comércio Internacional. Brasília: Instituto de Pesquisa Econômica Aplicada (IPEA), cap. 11, p.317-339.

BELL, M.; CASSIOLATO, J. E. (1993) The access of developing countires to new technologies: the need for new approaches to management and policy for technology imports in Brazilian industry. Estudo da Competitividade Brasileira. Campinas (SP).

BELLUZZO, L. G. (2013) “Os desafios da indústria brasileira”. Carta Capital, 4 de Março.

BESSANT, J.KAPLINSKY, R.ROSS, A.VAUGHAN, R.LAMMING, R. (1999) Using supply chains to transfer learning about best practices. Report to the Department of Trade and Industry. Brighton: Centre for Research in Innovation Management (CENTRIM), Brighton University.

BONELLI, R. (1998) "A note on foreign direct investment (FDI) and industrial competitiveness in Brazil”. Texto para Discussão n. 584. Brasília: Instituto de Pesquisa Econômica Aplicada (IPEA).

BRULAND, K. (1998) "Skills, learning and the international diffusion of technology: a perspective on Scandinavian industrialisation”. In: BERG, M. e BRULAND, K. (orgs.). Technological Revolutions in Europe: Historical Perspectives. Cheltenham: Edward Elgar, p.161-185.

CANO, W. (2012) “A desindustrialização no Brasil”. Economia \& Sociedade, v. 21, n. Número Especial, p. 831-851.

Carneiro, R. (2002) Desenvolvimento em crise: a economia brasileira no último quarto do século XIX. São Paulo: Editora UNESP.

CARNEIRO, R. (2007) “Globalização e integração periférica”. Texto para Discussão n. 126. Campinas (SP): Instituto de Economia (IE), Universidade Estadual de Campinas (UNICAMP).

CARRERE, M. H. (2011 [1975]) Producción, transferencia y adaptación de tecnología industrial. In: SABATO, J. A. (Orgs.). El pensamiento latinoamericano en la problemática ciencia-tecnología desarrollo-dependencia. Buenos Aires: Ediciones Biblioteca Nacional, cap. 15, p.347-380.

CASSIOLATO, J. E.; LASTRES, H. M. M. (2000) "Sistemas de inovação: políticas e perspectivas". Parcerias Estratégicas, v. 8, p. 237-255.

CASSIOLATO, J. E.; LASTRES, H. M. M.. (2005) Tecnoglobalismo e o papel dos esforços de PD\&I das multinacionais no mundo e no Brasil. Parcerias Estratégicas, v. 20.

CASSIOLATO, J. E.; LASTRES, H. M. M. (2014) "Inovação e desenvolvimento: a força e permanência das contribuições de Erber”. In: MONTEIRO FILHA, D.;PRADO, L. C. D., et al (orgs.). Estratégias de desenvolvimento, política industrial e inovação: ensaios em memória de Fábio Erber. Rio de Janeiro: BNDES, p.379-414.

CASSIOLATO, J. E.; SZAPIRO, M. (2015) "Os dilemas da política industrial e de inovação: os problemas da Região Sudeste são os do Brasil”. In: LEAL, C. F. C.;LINHARES, L., et al (orgs.). Um olhar territoral para o desenvolvimento: sudeste. Rio de Janeiro: BNDES, cap. 11, p.512p.

CASSIOLATO, J. E.ZUCOLOTO, G.MILAGRES, R.STALLIVIERI, F. (2014) “Transnational corporations and the Brazilian National System of Innovation”. In: CASSIOLATO, J. E.;ZUCOLOTO, G., et al (orgs.). Transnational corporations and local innovation. New Delhi: Routledge, p.68132. 
CHIARINI, T. (2014) Transferência internacional da tecnologia: interpretações e reflexões. O caso brasileiro no Paradigma das TICs na última década do século XX e no alvorecer do século XXI. 2014. (Tese de Doutorado). Instituto de Economia (IE), Universidade Estadual de Campinas (UNICAMP), Campinas (SP).

CIMOLI, M.PORCILE, G.PRIMI, A.VERGARA, S. (2005) "Cambio estructural, heterogeneidad productiva y tecnología en América Latina”. In: CIMOLI, M. (Orgs.). Heterogeneidad estructural, asimetrías tecnológicas y crecimiento en América Latina. Santiago: BID-CEPAL, 2005. p.9-39.

COOPER, C. (1972) "Science, technology and production in the underdeveloped countries: An introduction". The Journal of Development Studies, v. 9, n. 1, p. 1-18.

DAGNINO, R.; THOMAS, H.; DAVYT, A. (1996) "El pensamiento en ciencia, tecnología y sociedad en Latinoamérica: una interpretación política de su trayectoria”. REDES, v. 3, n. 7, p. 13-51.

DAHLMAN, C. J.; FRISCHTAK, C. R. (1990) National Systems supporting technical advance in industry: the Brazilian experience. Industry and Energy Department Working Paper, Industry Series Paper N. 32. Washington: The World Bank Industry and Energy Department.

DUNNING, J. H. (1994) "Multinational enterprises and the globalization of innovatory capacity". Research Policy, v. 23, p. 67-88.

ERBER, F. S. (2014) “Technological dependence and learning revisited”. In: MONTEIRO FILHA, D.;PRADO, L. C. D., et al (Orgs.). Estratégias de desenvolvimento, política industrial e inovação: ensaios em memória de Fabio Erber. Rio de Janeiro: BNDES, p.419-447.

FAJNZYLBER, F. (1983) La industrialización trunca de América Latina. Ciudad de Mexico: Editorial Nueva Imagen.

FRITSCH, W.; FRANCO, G. (1989) “O investimento direto estrangeiro em uma nova estratégia industrial”. Revista de Economia Política, v. 9, n. 2, p. 05-25,

GOMES, R. (2003) A internacionalização das atividades tecnológicas pelas empresas transnacionais. Elementos de organização industrial da economia da inovação. 2 (Tese de Doutorado). Instituto de Economia (IE), Universidade Estadual de Campinas (UNICAMP), Campinas (SP).

GONÇALVES, J. E. P. (2003) Empresas estrangeiras e transbordamentos de produtividade na indústria brasileira: 1997-2000. (Dissertação de Mestrado). Instituto de Economia (IE), Universidade Estadual de Campinas, Campinas (SP).

JAVORCIK, B. S. (2004) "Does foreign direct investment increase the productivity of domestic firms? In Search of spillovers through backward linkages”. The American Economic Review, v. 94, n. 3, p. 605-627.

KATZ, J. (2000) Pasado y presente del comportamiento tecnológico de América Latina. Serie Desarrollo Productivo de La CEPAL, n. 75. Santiago: División de Desarrollo Productivo y Empresarial de la CEPAL

KIM, L. (2005) “O sistema nacional de inovação sul-coreano em transição” In: KIM, L. e NELSON, R. R. (Orgs.). Technologia, aprendizado e inovação. As experiências das economias de industrialização recente. Campinas (SP): Editora da Unicamp, p.449-483.

KIM, L..(2005 [1997]) Da imitação à inovação: a dinâmica do aprendizado tecnológico da Coreia. Campinas (SP): Editora UNICAMP.

KUMAR, N. (1998) "Technology generation and technology transfers in the world economy: recent trends and implications for developing countries”. Science, Technology \& Society, v. 3, n. 2, p. 265-306,

LALL, S. (2004) Reinventing Industrial Strategy: The Role of Government Policy in Building Industrial Competitiveness G-24 Discussion Paper Series No. 28. Geneva: United Nations Conference on Trade and Development (UNCTAD)

LAPLANE, M.; SARTI, F. (1997) "Investimento direto estrangeiro e a retomada do crescimento sustentado nos anos 90”. Economia \& Sociedade, v. 8, p. 143-181.

LIM, E.-G. (2001) “Determinantes of, and the relation between, foreign direct investment and growth: a summary of the recent literature". IMF Working Paper n.01/175. Washington: International Monetary Fund (IMF)

LUNDVALL, B.-A.JOSEPH, K. J.VANG, J.CHAMINADE, C. (2009) “Innovation system research and 
developing countries”. In: LUNDVALL, B.-A.;JOSEPH, K. J., et al (Orgs.). Handbook of innovation systems and developing countries: building domestic capabilities in a global setting. Northampton (USA): Edward Elgar, p.1-32.

MALERBA, F.; ORSENIGO, L. (1993) "Technological regimes and firm behavior". Industrial and Corporate Change, v. 2, n. 1, p. 45-71.

MEDEIROS, C. A. (1997) "Globalização e inserção diferenciada da Ásia e da América Latina”. In: TAVARES, M. C. e FIORI, J. L. (Orgs.). Poder e Dinheiro: uma economia política da Globalização. Petrópolis: Editora Vozes, p.279-305.

MELLO, L. R. (1997) "Foreign direct investment in developing countries and growth: A selective survey". The Journal of Development Studies, v. 34, n. 1, p. 1-34.

MENDONÇA DE BARROS, J. R.; GOLDENSTEIN, L. (1997) “Avaliação do processo de reestruturação industrial brasileiro". Revista de Economia Política, v. 17, n. 2, p. 11-31.

MIRANDA, J. C. (2001) "Abertura Comercial, Reestruturação Industrial e Exportações Brasileiras na Década de 1990.” Texto para Discussão n. 829. Brasília: Instituto de Pesquisa Econômica Aplicada (IPEA). 2001

MUNIZ, S. (2000) “Investimento recente, capacitação tecnológica e competitividade". São Paulo em Perspectiva, v. 14, n. 3, p. 98-107

NEGRI, F. D. (2003) Desempenho comercial das empresas estrangeiras no Brasil na década de 90. (Dissertação de Mestrado). Instituto de Economia (IE), Universidade Estadual de Campinas (UNICAMP), Campinas (SP).

NEGRI, F. D..(2007) Investimento direto e transferência de tecnologia: Argentina, Brasil e México. (Tese de Doutorado). Instituto de Economia (IE), Universidade Estadual de Campinas (UNICAMP), Campinas (SP).

NELSON, R. R.; WRIGHT, G. (1992) "The rise and fall of American technological leadership: the postwar era in historical perspective. Journal of Economic Literature, v. 30, n. 4, p. 1931-1964.

NONNENBERG, M. J. B.; MENDONÇA, M. J. C. D. (2004) "Determinantes dos investimentos diretos externos em países em desenvolvimento. Texto para Discussão n. 1016. Brasília: Instituto de Pesquisa Econômica Aplicada (IPEA).

PACHECO, C. A.; ALMEIDA, J. G. D. (2013) “A política de inovação”. Texto para Discussão n. 210. Campinas (SP): Instituto de Economia (IE), Universidade Estadual de Campinas (UNICAMP).

PAULA, J. A. (2005) “A longa servidão: a trajetória do capitalismo no Brasil”. In: PAULA, J. A. (Orgs.). Adeus ao desenvolvimento: a opção do governo Lula. Belo Horizonte: Autêntica, p.17-36.

PUTMAN, R. D. (2005) Comunidade e democracia: a experiência da Itália moderna. Rio de Janeiro: Editora FGV.

RADOSEVIC, S. (1999) International technology transfer and catch-up in economic development. Cheltenham (UK): Edward Elgar.

RICUPERO, R. (2014) “Desindustrialização precoce: futuro ou presente do Brasil?” Le Monde Diplomatique. São Paulo. 06 de Março.

SARTI, F.; HIRATUKA, C. (2010) “Indústria mundial: mudanças e tendências recentes”. Texto para Discussão n. 186. Campinas (SP): Instituto de Economia (IE) da Universidade Estadual de Campinas (UNICAMP).

SARTI, F.; LAPLANE, M. (2002) “O investimento direto estrangeiro e a internacionalização da economia brasileira nos anos 1990”. Economia \& Sociedade, v. 11, n. 1, p. 63-94.

SILVEIRA, C. E. F. (2001) Desenvolvimento tecnológico no Brasil: autonomia e dependência num país periférico industrializado. (Tese de Doutorado). Instituto de Economia (IE), Universidade Estadual de Campinas (UNICAMP), Campinas (SP).

SOETE, L. (1985) "International Diffusion of technology, industrial development and technological leapfrogging." World Development, v. 13, n. 3, p. 409-422

TAVARES, M. C. (1981) Da substituição de importações ao capitalismo financeiro. Rio de Janeiro: Zahar Editores.

TEECE, D.; PISANO, G. (1994) “The dynamic capabilities of firms: an introduction”. Industrial and Corporate Change, v. 3, n. 3, p. 537-556,. 
THOMAS, H.DAVYT, A.GOMES, E.DAGNINO, R. (1997) "Racionalidades de la interacción Universidad-Empresa en América Latina (1955-1995)”. Educación Superior y Sociedad, v. 18, n. 1, p. $83-110$.

UNCTAD (2013) Global value chains: investment and trade for development. World Investment Report. Geneva: United Nations Conferece on Trade and Development (UNCTAD/UN).

VERA-VASSALLO, A. (1996) "La inversión extranjera y el desarrollo competitivo en América Latina y el Caribe.” Revista de la Cepal, v. 60, p. 129-149.

VIOTTI, E. B. (2002) "National learning systems: a new approach on technical change in late industrializing economies and evidences from the cases of Brazil and South Korea". Technological Forecasting \& Social Change, v. 69, p. 653-680. 